\title{
Out of the Shadows: A Review of Shadow Education and the Curriculum and Culture of Schooling in South Korea by Young Chun Kim
}

\author{
Val Mulholland \\ University of Regina
}

When I received the copy of Shadow Education and the Curriculum and Culture of Schooling in South Korean to review, I required a crash course in the system of supplementary schooling or private tutoring system (PTS) known as hakwon. I learned about practices, ideas, and beliefs that initially jarred my Western sense of $\mathrm{K}-12$ education. This was unfamiliar territory. The author Young Chun Kim promises a postcolonial reading of education in South Korea when recalling his early pledge to "become a scholar who studied Korean stories and schooling rather than US theories or knowledge and use them for answers for Korean education" (p. v). Thus, upon completion of his North American $\mathrm{PhD}$, he launched a distinguished career in his home country researching, conducting fieldwork, and writing, to acquire a comprehensive understanding of among other pursuits, how and why public schooling and hakwon intersect in South Korea.

After an initial reading of the book, I did some online sampling. Woonha Kim's Confessions of a Hakwon Insider, a TEDxYouth talk, is a popular example of available fare. As only a young person can do, Woonha claims to be an expert on hakwon because of his lived experience as a student in South Korea and his knowledge of the hakwon owned and operated by his parents. Young Chun Kim does not make such expansive claims; instead, he offers his extensive, thorough research to justify his argument. The author writes that South Korean curriculum studies have been dominated by Western ideas, and writes, "According to colonized notions of Korean pedagogy, uniquely Korean practices and experiences were invisible, neglected, or dismissed as unimportant" (p. 11). Ultimately, in the final chapters, he completes a case for the international field of Curriculum Studies to include systems of education different from the West, and to understand, in a contextualized way, why millions of people are dedicated to hakwon, a system that does not operate or look like Western school systems. He has devoted his career to understanding schooling in his country. Now he seems set on decolonizing Western ideas about education in South Korea.

\section{Summary}

The book begins with both a preface and prologue that set a purpose for writing that is appropriate for a book that purports to be a qualitative case study. It must be said it is the largest, most expansive case study I have ever encountered. Reminiscing about his graduate studies in the US, his subsequent career, and his goals to use postcolonial theory to make sense of his vast research in South Korea, he draws on completed work as well as additional interviews, observations, and document analysis to create the case study. The prologue describes a day in the life of a typical hakwon student that begins at 7:00 a.m. and ends in exhaustion at 11:00 p.m. Kim reports being troubled by the lived experience of the children in the study. He set this reader up to accept my first impression that the rigorous routine of hakwon is damaging to children. Nevertheless, in the comprehensive chapters to follow, which are devoted to history, statistical 
charts, curricula descriptions and interview data, the author sheds brighter light on the culture of hakwon.

Chapter 1 sets the globalized stage of education in South Korea, a country deeply invested in "world-class achievement" as measured by performance on PISA tests and by admission to highly prestigious post-secondary institutions. The tension between public schooling, which does not enjoy the confidence of Koreans, and hakwon, which certainly does, is a central theme of the book. "Like public school, hakwon education is a major part of Korean students' educational lives: even lay people in Korean tend to attribute the prowess of Korean students to their hakwon education rather than to public schooling" (p. 3). The perceived superiority of hakwon over public education is a guiding belief of the people. Parents put their money where their beliefs are, as evidenced by their personal spending on hakwon (PTS) of " 1.5 times the total public education budget. In Korea, the total expenditures for private tutoring is 24 billion dollars" (p. 5). Hakwon is serious business. Hakwons benefit from nimble business practices, which are designed to realize higher scores on tests, be more appealing to parents, but also to generate higher profits. To illustrate the conflation of cultural practice and financial support, Kim writes, "Koreans even have a saying that finding the best hakwon for her child is a mother's way to show her ability and affection as a parent" (p. 5). Originally, I thought I'd be most interested in the postcolonial theorizing promised in the opening passages, but instead I was dazzled by the numbers, by the statistics, by the stories of family investment of time, money and human resources to drive an economy with education, to create a future for South Korea. Hakwon is a metaphor for the post-WWII national success story.

\section{The History of Hakwon and its Manifestations}

Chapters 2 through 6 explain in detail the history of hakwon, including the South Korean government's futile efforts to ban hakwon outright, and to reform public education and national curriculum sufficiently to make hakwon education redundant, perhaps even undesirable, to the culture. Kim's claims are supported in the literature:

The growth of private tutoring service has been criticized for causing students' low engagement in school, placing a heavy financial burden on families, and contributing to overall education inequality. The South Korean government has thus sought over the years to implement various polices aimed to reduce the growing parent expenditure on private tutoring. (Lee \& Shouse, 2011, p. 212)

The economic and equity arguments against hakwon must contend with the historical legacy and the public confidence in PTS to make South Korea successful on the world stage (Bray \& Kwo, 2013). South Korea has endured hostile occupation by other nations, notably Japan. The Japanese rule of Korea ended in 1945-46. Hakwon, derived from the Chinese "place of learning," as a practice in Korea has Japanese origins. Culturally, education is linked to social mobility and status, the practice of hakwon has served to intensify competition in all school systems (Kim, p. 126). Competition for admission to university in Korean is fierce, and since the lift on the Hakwon ban in 1992, has increased as the lure of admission to prestigious international universities has entered the fray. 
Since 1961, the government of South Korea has tried everything to strengthen confidence in public schools, as well has made efforts to limit or ban Hakwon. Initially, the history of hakwon in Korea to me seemed like a primer on the perils of large school tests for the purposes of social stratification; however the confidence in, and commitment to, large scale testing as a certain measure of academic success appears to be unquestioned, even by the author (p. 137). Couple the pressure to compete for prestigious placement at the leading national universities (only $4 \%$ of students are accepted to the top university) with a pre-existing entrepreneurial spirit, laced with an insatiable appetite for perceived social and economic advantage offered by education, and you have a runaway train of national ambition. From evidence provided in the book, hakwon does not appear to be going anywhere, other than to the next perceived level of achievement.

Chapter 3, devoted to the most prevalent types of hakwon, identifies the three-legged stool of hakwon success: focus on the test; studying harder; and the future. It's a heady combination. The national effort to "study to the test" is breathtaking (p. 90, 131). Hakwon sessions (which may be group classes, individual tutoring, or supported learning online) begin after public school is finished at mid-afternoon. After a brief break for a meal, the hakwons run until $8-11 \mathrm{p} . \mathrm{m}$. depending on the age of the children. Many of the large successful hakwons have their own bus systems. If that's not sufficient evidence for the support of "study harder" ethos, consider that many students in the final years of high school spend $10-12$ hours per day at hakwons on the weekend cramming for the tests. Academic credentials are considered the passport to successful adult life (Kim, p. 126). Apart from public confidence, the author shows repeatedly throughout the text that hakwons are free of many of the restrictions that public schools must adhere to. So, as individual businesses, not official institutions of learning, hakwons are able to experiment with innovative teaching methods, develop their own textbooks designed to breakdown the national curriculum into digestible pieces, operate with smaller class sizes, and adopt unregulated hiring practices. Even physical punishment is allowed in hakwon. The practice of hakwon is prevalent throughout southeast Asia, to India and beyond, and presents ethical dilemmas for Western researchers in education (Yung, 2015).

Kim reports that the ubiquitous presence of hakwons has had deleterious effects on public schools. For example, I found it troubling that public teachers' expect that students will learn difficult content at the hakwon, therefore relieving them from providing adequate instruction ( $\mathrm{p}$. 36). Kim (2016) notes,

The biggest difference between hakwon instructors and school teachers in Korea is the security of their jobs: when one becomes a schoolteacher he or she can remain in the job for the rest of their lives; however, if hakwon instructors fail to provide their ability to teach, they fall behind and consequently the might lose their jobs." (p. 187)

Hakwon teachers must compete for student and parental approval. The freedom from government regulations also means that hakwons can create homogenous student populations through selection, ability grouping, as well as subject and student interest specialization. In contrast, public schools must accept all students and teach the national curriculum. 
It's not an overstatement to say that I was gobsmacked by the details of how hakwons operated as businesses, and how much pressure is put on the students subjected to compete for post-secondary placements. Anecdotally, a graduate student who taught in several hakwons told me that the day that university acceptance results are shared is known as Suicide Day. Also amazing were the variety of hakwons. There are English hakwons, math hakwons, boardingschool hakwons, deluxe hakwons, cut-rate hakwons, and the increasingly popular online hakwons for every grade level. Only the most impoverished students in the country do not participate in hakwons. To some extent, government concern for equal access to education drove the efforts to control hakwons, but the efforts were unsuccessful. Kim also alludes to the inherent inequities of a privately financed shadow system, but acknowledges that parents' belief that children have the best future prospects through the best possible education is paramount. Parental investment in hakwon is a type of retirement saving because adult children have some measure of responsibility for the care of aging parents. The desire for superior education is complex.

\section{Structure of the Argument}

The organization of the dense information-laden chapters is logical; the style is accessible, with topic sentences followed by numbered points of supporting information. Kim claims the book represents a "first international qualitative case study on hakwon education, and thus, might be used as a guiding example for succeeding research" (p. 196). The site for the case study is massive, including numerous public schools and hakwons in Korea. Kim admits,

Fortunately, I was able to collect extensive data since I am a native Korean, know the educational systems very well, and had visited them many times for prior research... Since my research objective was to understand the positive roles of hakwon education, the research participants were friendly and helpful. (p. 196)

No doubt, given the lingering motive of profit in hakwon. Acknowledging that readers who lack his insider perspectives, like me, who may carry preconceived unfounded notions, like me, he writes: "I hesitated to present images of Korean education which were not familiar to readers and were opposite to their previous perceptions" (p. 197). He goes on to say that he anticipated international readers might be shocked by the additional time students spend at hakwons, and consider this practice "not educationally or developmentally appropriate" (p. 197). Guilty as charged.

The last two chapters comprise the argument alluded to in the opening chapter. Kim confronts the inherent tensions in the present South Korean educational system, and he has provided extensive, in-depth description of the programs, and to some extent the experiences of the students and teachers. He addresses the issues of inequality, international misconception, and cultural stereotypes that result when the whole society is "teaching to the test." He offers new images to displace existing stereotypes. Readers might see the following from reading his book: that hakwons threaten public education; that hakwon education prevails, creating a second life for students; "that education is bought and sold for commercial purposes, that it is advertised as a commodity like cars and clothes, and if you have more money, you can buy better products;" and finally; that "students are obsessed with competition and survival" and see hakwon as the best 
way forward (p. 197). Kim predicts that Western readers may see his findings as "Strange? Primitive? Unproductive? Too competitive? Underdeveloped?” (p. 197). At first reading, I did.

Taking up postcolonial theory of the Other, and fortified with Deleuze's notion of the "body without organs," in the concluding chapter "Questions without Organs" (p. 198), the author launches his argument in full. Yes, two school systems exist in Korea and it's impossible to see one without the other. It's a case of this and that. He challenges curriculum theorists to ask what he calls untraditional questions, to look beyond their preconceived assumptions and stereotypes of the "Far East." He marshals Pinar's (1994) theory of currere to challenge researchers to see hakwon in richer, more descriptive ways. He asks curriculum researchers to consider how Korean education is positioned as Other in Western scholarship. Failing to do so is to deny what hakwons do well: to engage students in superior educational achievement. Western scholars are urged not to perceive South Korean education from a negative perspective,

simply because it is Oriental and unfamiliar to scholars in the West; simply because it is the other and is marginalized from our perceptions of schools as central and legitimate; simply because it is opposite to the basic philosophy of education in the West which emphasizes progressive education and a child-centered curriculum. (p. 201)

It's a big finish. Am I completely convinced? Not entirely, but I continue to think about how I have been trained to see what I see in schools. Perhaps in the face of my own chasm of ignorance, I need to readjust the lens.

\section{Conclusion}

Before Western readers like me take too smug an attitude about the harsh rigours of hakwon's reputation for teaching to the test, we may wish to consider how similar programming outside of school exists to benefit children from affluent families in much of North America. Many in the West believe that extracurricular activities determine success in later life, or consider the money to fund recreational hockey, a largely private organized sport in most jurisdictions, an investment to chase the dream of an NHL career. Investing in dreams to fulfill parents' aspirations appears to be pervasive beyond South Korean borders. Before reading this book, I knew precious little about transnational experiences of private tutoring, class anxiety, academic competition, and cultural conflict. Kim's book taught me a great deal, and caused me to notice more about misinformed assumptions that circulate in my educational community.

As luck would have it, a former graduate student had been a teacher in South Korean hakwons for a number of years. I called her. She described her experience as a hakwon teacher as life-changing, for the cultural knowledge gained through immersion in a different style of education. Originally hired to provide students with "natural conversation," her native-English speaker status gained her a teaching position before she had Canadian certification. The opportunity to travel, to make a good salary, to gain teaching experience set her up for a successful career as a teacher and administrator back home in North America. Her rich description of life at the hakwon mirrored much of what I read in Shadow Education. She affirmed that children were often tired, during the additional hours of evening instruction, especially so for high school students whose days were longest. Students did achieve amazing 
results. She noted also that hakwon counsellors taught mindfulness to teach self-discipline and self-control, which were beneficial to students and teachers. The hakwon and student families shared the values of saving face, family honour and status, which made for a unified learning community. My skepticism lurked in my questions. Finally, I asked the predictable question, would you send your own children to a hakwon? She said yes.

In recent years, a New York-based, self-declared Tiger Mom has gained significant press attention for her theory of raising exceptional children. Reading Shadow Education and the Curriculum and Culture of Schooling in South Korea, reminded me of her recipe for accomplished children. Hakwons are "a major social policy issue in East Asia, and particularly South Korea" (Lee \& Shouse, 2011, p. 212). Unsurprisingly, a form of hakwon has migrated to the coasts of continental U.S.: "Korean migrants to the United States largely retain the mentality that admission to prestigious universities is the surest route to success" (Yi, 2013, p.190). Yi invokes the Tiger Mom stereotype, and posits a new stereotype, the Liberal Elephant, as a Western counterpoint that contests the hakwon philosophy. When Korean immigrant parents attempt to import hakwon to the U.S., they come up against a liberal humanist culture that purports to value individual interests, talents, and growth, which Yi suggests is a cause supported by actively proselytizing Christian churches. The liberal elephants resist the cultural belief in hakwon: "Caught between Tiger Moms and Liberal Elephants, many Korean immigrant parents seemed to genuinely struggle over the way to raise their children in America" (Yi, 2013, p. 194). I think I came to this book as a liberal elephant with a good deal to learn.

Kim emphasized from the onset that hakwon education was worthy of serious research in the Western-dominated field of curriculum studies. Initially, I was mesmerized by Gangnam Style entrepreneurship of hakwon. Kim has written 39 other books, and more than 50 articles, on South Korean education. He has a lot to say. I acknowledge his expertise, and continue to come to terms with how my cultural beliefs were a barrier to understanding the book. 


\section{References}

Bray, M., \& Kwo, O. (2013). Behind the façade of fee-free education: Shadow education and its implication for social justice. Oxford Review of Education, 39(4), 480-497. doi:10.1080/03054985.2013.82152

Kim, Y. C. (2016). Out of the shadows: A review of shadow education and the curriculum and culture of schooling in South Korea. London, UK: PalgraveMacMillan.

Lee, S., \& Shouse, R.C. (2011). The impact of prestige orientation on shadow education in South Korea. Sociology of Education, 84(3), 212-224.

Yi, J. (2013). Tiger moms and liberal elephants: Private, supplemental education among KoreanAmericans. Global Society, 50, 190-195. doi: 10.1007/s12114-013-9638-0

Yung, K.W.H. (2015). Ethical dilemmas in shadow education research: Lessons from a qualitative study of learners' experiences in lecture-type tutoring in Hong Kong. In M. Bray et al. (Eds.), Researching Private Supplementary Tutoring, pp. 97-114. CERC Studies in Comparative Education, 32. 